Priyambodo *) Optimalisasi.Tingkat Pelayanan .....

\title{
OPTIMALISASI TINGKAT PELAYANAN JALAN LINTAS PORONG
}

\author{
Naskah diterima Tgl 7 Januari 2011, Naskah disetujui Tgl 30 Novémber 2011 \\ Priyambodo *) \\ : Email : pridenantes@yahoo.co.id
}

\begin{abstract}
ABSTRAK
Maksud dari penelitian ini adalah untuk memberikan gambaran aksesibilitas dan tingkat pelayanan jalan dari sentra industri kecil dan menengah di Jawa Timur mernju daerah pemasarannya yang kondisinya terganggu sejak terjadinya bencana lumpur Lapindo di Sidoarjo talun 2006. Metode yang digunakan dalam analisis adalah metode analisis VCR dan analisis aksesibilitas. Hasil penetitian menunjukkan bahwa 40 persen kondisi jalan mulai dari Bangil - Pasuruan - Probolinggo - Situbondo - Banyuwangi adalah bergelombang dan kurang dilengkapi dengan fasilitas perambuan. Sementara kondisi jalan di lintasan tengah dan selatan, yaitu Probolinggo - Lumajang - Jember relative lebih baik, tetapi fasilitas perambuan masil kurang. Titik kemacetan terjadi antara lain di daerah Singosari lebih disebabkan karena banyaknya orang yang menyeberang jalan karena tidak adanya jembiatan penyeherangan orang. Tingkat aksesibilitas di Pandaan, Ngoro, dan Bangil menuju Surabaya yang melewati jalur Porong - Gempol berdasarkan persepsi responden berkisar antara 3.3 sampai 3.5, artinya bahrwa tingkat aksesibilitas di lintasan ini bagus. VCR yang dilitung di lintasan Gedangan - Surabaya pulang pergi menunjukkan angka 1.2 dan 13, artinya di lintasan Gedangan - Surabaya atau sebaliknya tingkat pelayanan jalanmya dalam kategori $F$, artinya kondisi VCR di lintasan tersebut macet total. Titik-titik kemacetan lain terjadi juga pada lintasan Porong - Gempol dengan nilai 0.75 , ini tingkat pelayanan jalannya dalam kategori $D$. Tetapi kondisi tahun 2009 tingkat pelayanan jalan lintas Porong - Gempol lebil baik dari pada tahun 2008. Ini disebabkan karena pengelolaan yang baik atas jalan-jalan alternatif.
\end{abstract}

Kata kunci : sentra industri kecil dan menengah, tingkat pelayanan jalan, aksesibilitas.

\begin{abstract}
The aim of the research is to give description pf roads' accessibility and level of service from the centers of small and medium industries in East Java to the inarket area over a roadway of Porong. Methods of data analysis used are the VCR and accessibility analysis. This study has shown that 40 percent of road conditions of Bangil - Pasuruan - Probolinggo - Situbondo Bamyuwangi are bumpy and less equipped with adequate beaconing facilities. While the condition of roads in central and Southern cross, namely Probolinggo - Lumajang - Jember are relatively better. But the beaconing facility condition was still not adequiate. Serious congestion occurs in the area of Singosari due to many people cross the road. It is caused by the absence of a crossing bridge for the people in the region. Accessibility level of Paridaan, Ngoro, and Bangil headed to Surabaya past the trajectory Porong - Gempol which is calculated based on the user's
\end{abstract}

*) Peneliti Puda Balitbang Provinsi Jawa Timur 
perception of these lines ranged between 3.3 and 3.5 which mean that the level of accessibility on the track is good. The VCRs which are counted in Gedangan - Surabaya and vice versa shows figures 1.2 1nd 1.3 which means that the traffic situation on both of these point are in category F, which mean total traffic jam. Other congestion points occur also in the path Porong - Gempol with a value of 0.75 VCR. It is includ in in category D. but in 2009 the level of service on track Porong - Gempol increased from the yeu 2008, due to care and proper management of alternative roads.

Key words: Industries centers of amall and medium industries, level of road service, and accessibility.

\section{PENDAHULUAN}

Provinsi Jawa Timur sejak dulu telah dikenal sebagai daerah Indamardi, yaitu daerah industri, perdagangan, maritim, dan pendidikan. Sebutan Jawa Timur sebagai daerah Indamardi telah melekat sejak puluhan tahun yang lalu. Sebagai sebuah provinsi di Indonesia yang letaknya di tengah-tengah gugusan kepulauan di Indonesia menyebabkan Provinsi Jawa Timur disiapkan oleh Pemerintah Pusat menjadi pintu gerbang kegiatan perekonomian dan perdagangan serta industri untuk kawasan Indonesia bagian timur.

Namun posisi Jawa Timur sebagai pintu gerbang kegiatan perekonomian dan perdagangan serta perindustrian untuk Indonesia bagian timur sejak tahun 2006 mulai sedikit terguncang ketika ada semburan lumpur lapindo lima tahun yang lalu. Akibatnya jalur transportasi di lintas Tol Porong Gempol menjadi terputus.

Terputusnya jalur ini menyebabkan jalur transportasi dari dan ke sentrasentra industri di wilayah timur dan selatan Surabaya menuju ke daerah pemasaran menjadi terganggu. Sebab ruas jalan Tol Porong - Gempol merupakan satu-satunya akses menuju Surabaya atau Pelabuhan Tanjung Perak dari segala penjuru daerah Jawa Timur bagian timur maupun selatan.

Sebelum terjadi semburan lumpur panas Lapindo distribusi barang, jasa, dan orang dari arah timur seperti Banyuwangi sampai Surabaya melewati ruas Tol Porong - Gempol berlangsung relatif aman, lancar, dan normal. Begitu juga dari arah selatan, mulai Jember menuju Surabaya lewat Lumajang dan Malang yang juga melewati ruas Tol Porong - Gempol kondisi lalu lintasnya kurang lebih juga sama, yaitu aman, lancar, dan normal.

Sementara konsentrasi sentra-sentra industri di Jawa Timur terbagi dalam empat kawasan, yaitu kawasan barat, adalah Surabaya, Gresik, Lamongan, Tuban, dan Bojonegoro. Kawasan tengah adalah Mojokerto, Jombang, Nganjuk, dan Kediri. Kawasan selatan adalah Batu, Malang, dan Lumajang. Dan kawasan timur adalah Pasuruan, Probolinggo sampai Banyuwangi.

Dari empat kawasan tersebut di atas barang dan jasa serta orang yang pasti melewati ruas Tol Porong adalah barang dan jasa serta orang yang berasal dari kawasan timur dan selatan. Jadi bisa dibayangkan atas putusnya ruas Tol Porong - Gempol tersebut. Puluhan sentra-sentra industri yang terletak disekitar Pasuruan, Probolinggo, Batu 
dan Pandaan menjadi terganggu aksesibilitas dan koneksitasnya jika produk-produk mereka harus dipasarkan atau dikapalkan melalui Pelabuhan Tanjung Perak.

Kini setelah tragedi semburan lumpur Lapindo memasuki tahun ke lima pemerintah pun, baik pemerintah pusat, regional, mau pun lokal telah berupaya memulihkan jalur transportasi di lintasan Porong, meskipun sampai hari ini pemulihannya masih bersifat tambal sulam. Sementara untuk pembangunan jalan Tol baru ruas Porong Gempol sepanjang 9,5 Km masih belum selesai.

Sebagaimana dalam teori transportasi, bahwa aksesibilitas yang tinggi berarti ada kemudahan dari suatu barang, jasa atau orang berpindah dari suatu tempat ketempat lain, begitu juga sebaliknya yang berimplikasi pada efisiensi yaitu waktu tempuh dan biaya. Sehingga akan muncul nilai-nilai kegunaan barang atau jasa seperti time utility (nilai guna waktu), place utility (nilai guna tempat), maupun produk utility (nilai guna produk).

Begitu juga dengan tingkat pelayanan jalan yang diformulaikan sebagai perbandingan antara volume kendaraan dengan kapasitas jalan. Semakin tinggi volume kendaraan yang lewat maka tingkat pelayanan jalan tersebut semakin rendah, begitu juga sebaliknya. Artinya semakin rendah tingkat pelayanan jalan maka biaya dan waktu yang dikeluarkan oleh pengguna jalan (industri-industri kecil) akan semakin tinggi dan lama begitu juga sebaliknya.

Jadi aksesibilitas adalah konsep yang menggabungkan sistem pengaturan tata guna lahan secara geografis dengan sistem jaringan transportasi yang menghubungkannya. Aksesibilitas adalah suatu ukuran kenyamanan atau kemudahan mengenai cara lokasi atau tata guna lahan berinteraksi satu sama lain dan "mudah" atau "susah" nya lokasi tersebut dicapai melalui sistem jaringan transportasi (Black, 1981) dalam Ofyar Z. Tamin, 2000.

Faktor-faktor yang menentukan tinggi rendahnya aksesibilitas (tingkat kemudahan pencapaian tujuan) menurut Fidel Miro dipengaruhi oleh : faktor waktu tempuh, biaya/ongkos perjalanan, intensitas (kepadatan) guna lahan, pendapatan orang yang melakukan perjalanan. Secara matematis atau terukur (kuantitatif) tingkat aksesibilitas (kemudahan pencapaian) lokasi tujuan dapat ditentukan dengan rumus (Black, 1981 dan Hansen, 1959) sebagai berikut:

$$
K_{i}=\sum_{d=1}^{N} A_{d}
$$

$K_{i}=$ aksesibilitas zona $i$ ke zona lainnya $(d)$

$A_{\alpha}=$ ukuran aktivitas pada setiap zona $d$ (misalnyajumlah lapangan kerja)

$t_{i d}=$ ukuran waktu atau biaya dari zona asal $i$ ke zona tujuand

$\mathrm{N}=$ Banyaknya zona tujuan $i$ sesuai dengan kegiatan orang dalam wilayah kota

Selanjutnya untuk mengukur tingkat aksesibilitas secara kuantitatif (kualitatif yang dikuantitatifkan) dapat dilakukan dengan survey persepsi pengguna jasa terhadap kondisi pelayanan transportasi berdasarkan indikator aksesibilitas yang ada. Responden diminta untuk memberikan penilaian terhadap preferensi yang dirasakan atas pelayanan jasa yang dirasakan, dengan 
Jurnal Cakrawala Vol.6 No.1 Desember 2011: 1 - 15

nilai (kuantitatif):

1. untuk sangat jelek

2. untuk jelek

3. sedang

4. baik

5. sangat baik

Sementara tingkat pelayanan jalan

atau dikenal dengan VCR dapat dihitung dengan rumus:

$$
\text { VCR } \cdot \frac{V}{C}
$$

VCR = Indeks tingkat pelayanan jalan

$\mathrm{V} \quad=$ Volume lalu lintas jalan $(\mathrm{smp}$ per jam)

$\mathrm{C}=$ Kapasitasjalan (smp per jam)

Kapasitas jalan adalah volume maksimum kendaraan yang dapat melintas pada suatu ruas jalan tertentu dengan satuan SMP per jam. Besarnya kapasitas jalan biasanya dipengaruhi oleh beberapa faktor antara lain adalah (1) jumlah dan lebar lajur; (2) kecepatan rencana; (3) gangguan samping; (4) jenis perkerasan permukaan jalan (E.K. Morlock).

Rumus kapasitas jalan menurut Manual Kapasitas Jalan Indonesia (MKJI) adalah sebagai berikut.

Kapasitas Perkotaan :

$C=\operatorname{CoXFCw} \times$ FCsp $X$ FCsf $X$ $\mathrm{FCcs}$ (smp/jam)

Kapasitas Luar Kota :

$C=\operatorname{CoXFCw} \times$ FCsp $\times$ FCsf (smp/jam)

Keterangan :

C - Kapasitas

$\mathrm{Co}=$ Kapasitas Dasar (smp/jam)
$\mathrm{FCw}=$ Faktor Penyesuaian Lebar Jalur Lalu-Lintas

FCsp $=$ Faktor Penyesuaian Pemisah Arah

FCsf $=$ Faktor Penyesuaian Hambatan Samping

Fccs $=$ Faktor Penyesuaian Ukuran Kota

Atas dasar penting dan vitalnya ruas jalan lintas Porong - Gempol yang menghubungkan Pelabuhan Tanjung Perak dengan sentra-sentra industri di wilayah Jatim, maka rumusan masalah dalam penelitian ini adalah bagaimana kondisi aksesibilitas dan tingkat pelayanan jalan lintas Porong dari sentrasentra industri menuju daerah pemasaran serta bagaimana mengoptimalkan tingkat pelayanan jalan lintas Porong.

Adapun tujuan dari penelitian ini adalah untuk mengetahui kondisi aksesibilitas dan tingkat pelayanan jalan lintas Porong dari sentra-sentra industri menuju daerah pemasaran serta untuk menjamin kelancaran arus barang dan jasa dari sentra-sentra industri di wilayah timur dan selatan Surabaya yang menuju daerah pemasaran.

Keluaran dari penelitian ini di harapkan dapat memberikan informasi kepada Pemerintah Provinsi Jawa Timur dan pelaku-pelaku ekonomi di Jawa Timur khususnya dari daerah selatan dan timur Surabaya agar ikut mengupayakan kelancaran arus lalu lintas barang, jasa, dan orang dari sentra-sentra industri menuju daerah pemasaran.

Hasil penelitian ini dapat digunakan sebagai bahan masukan atas program recovery dan rekonstruksi jalur transportasi lintas Porong-Gempol. Sementara manfaat dari penelitian ini adalah mewujudkan koneksitas dan aksesibilitas transportasi yang aman, nyaman, mudah, murah, dan 
terjangkau di Jawa 'limur khususnya yang melintasi Porong-Gempol menuju daerah pemasaran.

\section{METODE PENELITIAN}

Jenis penelitian ini ditinjau dari segi manfaatnya adalah penelitian terapan. Berdasarkan tujuan penelitian adalah penelitian deskriptif. Penelitian ini termasuk penelitian yang menggunakan metode kuantitatif dimana pengukuran datanya menggunakan angka-angka.

Dalam penelitian ini digunakan pendekatan kuantitatif dimana datadata sekunder dan primer dicari dan diukur dengan skala ratio dan interval.

Populasi dalam penelitian ini untuk menghitung VCR secara kuantitatif berupa rute ruas jalan dan satuan mobil penumpang (SMP) serta sopir angkutan barang. Sementara untuk menghitung aksesibilitasnya menggunakan persepsi responden (sopir truk) dengan rute dari sentra-sentra industri yang melewati ruas jalan lintas Porong menuju pelabuhan Tanjung Perak. Dengan jumlah sampel sebanyak 60 responden.

Sampel data primer diambil pada ruas-ruas jalan yang telah ditentukan yaitu:

a. Surabaya - Sidoarjo (menghitung VCR di titik Gedangan dan Tol Gunung Sahari yang menuju ke Pelabuhan Tanjung Perak);

b. Surabaya - Malang (menghitung VCR di titik Porong-Gempol)

c. Sidoarjo - Pasuruan (menghitung VCR dititik Bangil);

d. Probolinggo - Situbondo dan Bondowoso (menghitung VCR di titik Kraksaan);

e. Surabaya - Malang (menghitung VCR di titik Pandaan dan Singosari);

f. Mojokerto - Porong (menghitung
VCR di titik Ngoro)

Menghitung aksesibilitas (persepsi 60 sopir perusahaan industri serta melakukan pengamatan) pada lintasan:

a. Sidoarjo-Pasuruan di titik Bangil;

b. Sidoarjo-Malang dititik Pandaan;

c. Pasuruan - Probolinggo di titik Rejoso;

d. Sidoarjo-Malang dititikSingosari;

Sementara data sekunder yang diperlukan adalah data tentang lokasi sentra-sentra industri (di Pasuruan, Probolinggo, Malang, Lumajang, dan Jember) dan rute jalan dari sentra-sentra industri menuju Pelabuhan Tanjung Perak.

Dalam penelitian ini langkah pertama yang dilakukan adalah mencari data primer dan sekunder. Data primer yang dimaksud adalah data tentang tingkat pelayanan jalan lintas Porong dari sentra-sentra industri ke Pelabuhan Tanjung Perak dan data tentang aksesibilitas jalan lintas Porong dari sentra-sentra industri ke Pelabuhan Tanjung Perak. Data primer diperoleh dengan cara menghitung dan mengukur langsung di lapangan.

Data sekunder adalah data tentang sentra-sentra industri, peta jaringan jalan, dan peta jalan-jalan alternatif. Data sekunder diperoleh dengan cara meminta dan mendatangi langsung sumber-sumber data, yaitu ke Dinas Perhubungan Provinsi Jawa Timur, Surabaya, Sidoarjo, Pasuruan, Probolinggo, Malang, Lumajang, dan Jember.

Data primer dan sekunder yang telah terkumpul lalu dievaluasi untuk dipakai sebagai bahan analisis lanjutan serta dipakai sebagai alat untuk menyusun rekomendasi. Data-data tersebut dianalisis dengan menggunakan analisis tingkat pelayanan jalan dan aksesibilitas serta analisis deskriptif. 
Jurnal Cakrawala Vol.6 No.1 Desember 2071 : 1 - 15

\section{ANALISA DAN PEMBAHASAN}

A. Karakteristik Sentra-Sentra Industri dan Daerah Pemasaran

Karakteristik sentra-sentra industri kecil dan menengah serta pemasaran hasil-hasil industri di lokasi penelitian, yaitu di kabupaten / Kota Pasuruan, Probolinggo, Malang, Lumajang, dan Jember dapat diuraikan sebagai berikut

Tabel 1

Karakteristik Sentra-Sentra Industri Kecil dan Menengah Tahun 2009

\begin{tabular}{|c|c|c|c|c|c|c|}
\hline No & Kota/Kab. & Kecamatan & Jumlah & Jenis & Nilai Investasi & $\begin{array}{c}\text { Daerah } \\
\text { Pemasaran }\end{array}$ \\
\hline 1 & Pasuruan & $\begin{array}{l}\text { Beji, Bangil. Puspo, } \\
\text { Keraton } \\
\text { Rejoso, Grati. } \\
\text { Nguling. Lumbang, } \\
\text { Winongan, } \\
\text { Gondang, } \\
\text { Purwodadi, } \\
\text { Porwosari. } \\
\text { Sukorjo, Wonorejo, } \\
\text { Pandaan, Rembang. } \\
\text { Pohjentrek } \\
\text { Tutur, Kejayan, } \\
\text { Gempol, Purworejo, } \\
\text { Gadingrejo, Bagul }\end{array}$ & $\begin{array}{l}7.634 \\
\text { unit }\end{array}$ & $\begin{array}{l}\text { kerajinan, } \\
\text { makanan ola } \\
\text { han, bordir. batu } \\
\text { bata. } \\
\text { mebel, konveksi, } \\
\text { perhiasan. } \\
\text { anyaman, batik, } \\
\text { tenun, genteng. } \\
\text { logam, gerabah, } \\
\text { pande }\end{array}$ & $\begin{array}{c}\text { Rp. } \\
89,973,670,000\end{array}$ & $\begin{array}{l}\text { Lokal. regional. } \\
\text { nasional } \\
\text { Dan } \\
\text { international }\end{array}$ \\
\hline 2 & Probolinggo & $\begin{array}{l}\text { Sukapura, Kuripan, } \\
\text { Bantaran } \\
\text { Leces, } \\
\text { Tegalsiwala, } \\
\text { Banyuanyar, Tirir. } \\
\text { Krucil, } \\
\text { Gading. Pakuniran. } \\
\text { Kotaanyar } \\
\text { Paiton, Besuk. } \\
\text { Kraksaan, } \\
\text { Krenjengan, } \\
\text { Pajarakan } \\
\text { Maron, (iending, } \\
\text { Dringu, } \\
\text { Wonomerto, } \\
\text { Tongas, } \\
\text { Sumberasih }\end{array}$ & $\begin{array}{l}1.658 \\
\text { unit }\end{array}$ & $\begin{array}{l}\text { Kerajinan, pande } \\
\text { besi. } \\
\text { genteng, mebel. } \\
\text { honveksi } \\
\text { penggergajian } \\
\text { kayu. } \\
\text { makanan olahan. } \\
\text { kasur. } \\
\text { gula aren, bordir; } \\
\text { batu bata. gerabah. } \\
\text { garam, terasi }\end{array}$ & $\frac{\mathrm{Rp} .}{2.991 .301,000}$ & $\begin{array}{l}88 \% \text { dipasarkan } \\
\text { di pasaran lokal } \\
23 \% \text { dipasarkan } \\
\text { di pasaran. } \\
\text { regional } \\
\text { khusus bordir } \\
40 \% \text { dipasarkan } \\
\text { di luar negeri } \\
\text { Scperti Lropa } \\
\text { limur. Tengah } \\
\text { \& Amerika }\end{array}$ \\
\hline
\end{tabular}




\begin{tabular}{|c|c|c|c|c|c|c|}
\hline 3 & Malang & $\begin{array}{l}\text { Karangploso, } \\
\text { Gondanglegi, } \\
\text { Turen, Pakis, } \\
\text { Donomulyo, } \\
\text { Kepanjen, } \\
\text { Tumpang, Singo } \\
\text { sari, Bululawang, } \\
\text { Sumber } \\
\text { manjing wetan, } \\
\text { Pagak, Dau } \\
\text { Lawang, } \\
\text { Poncokusumo, } \\
\text { Dampit, Wajak, } \\
\text { Ngantang, } \\
\text { Pakisaji, Wonosari, } \\
\text { Blimbing, Kedung } \\
\text { kandang, Klojen, } \\
\text { Lowok waru, Sukun }\end{array}$ & $\begin{array}{c}2.326 \\
\text { unit }\end{array}$ & $\begin{array}{l}\text { makanan olahan } \\
\text { seperti } \\
\text { tempe, bordir, } \\
\text { kulit, genteng, } \\
\text { kapur, } \\
\text { keramik, } \\
\text { kayu, kasur, } \\
\text { klompen, } \\
\text { mendong, bambu, } \\
\text { anyaman } \\
\text { bambu, kerai } \\
\text { rotan, kerai } \\
\text { mendong, } \\
\text { kompor, pande } \\
\text { besi, mebel rotan, } \\
\text { sanitair }\end{array}$ & $\begin{array}{c}\mathrm{Rp} \\
19,907,069,000\end{array}$ & $\begin{array}{l}59 \% \text { dipasarkan } \\
\text { di pasaran lokal } \\
40 \% \\
\text { dipasarkan } \\
\text { regional, dan } \\
25 \% \text { dipasarkan } \\
\text { nasional }\end{array}$ \\
\hline 4 & Lumajang & $\begin{array}{l}\text { Candipuro, Pasirian, } \\
\text { tempe, } \\
\text { Pasrujambc, } \\
\text { Lumajang, Kla } \\
\text { kah, Yosowilangun, } \\
\text { Tempur } \\
\text { sari, Kunir, Tekung, } \\
\text { Sendu } \\
\text { Ranuyoso, Gucialit, } \\
\text { Pronoji } \\
\text { wo, Kedungiajar, } \\
\text { Sumber, } \\
\text { Jatiroto, Sukodono, } \\
\text { Padang }\end{array}$ & $\begin{array}{c}2.520 \\
\text { unit }\end{array}$ & $\begin{array}{l}\text { gula kelapa, } \\
\text { tempe tahu, } \\
\text { kcripik, roti, } \\
\text { anyaman } \\
\text { bambu, sapu ijuk, } \\
\text { tas, } \\
\text { dompet, mebel } \\
\text { kayu, kerajinan } \\
\text { perak, } \\
\text { pande besi } \\
\text { kompor, genteng, } \\
\text { bordir, } \\
\text { kerajinan bambu, } \\
\text { kasur }\end{array}$ & $\begin{array}{c}\mathrm{Rp} \\
2,846,785,000\end{array}$ & $\begin{array}{l}57 \% \text { dipasarkan } \\
\text { di pasaran } \\
\text { lokal, } 33 \\
\% \text { di pasar } \\
\text { regional, dan } \\
15 \% \\
\text { dipasaran } \\
\text { nasional }\end{array}$ \\
\hline 5 & Jember & $\begin{array}{l}\text { Tempurejo, } \\
\text { Wuluhan, Panti, } \\
\text { Puger, Mayang, } \\
\text { Silo, Bang } \\
\text { salsari, Sumberbaru, } \\
\text { Bang, } \\
\text { salsari, Patrang, } \\
\text { Kaliwates, } \\
\text { Arjasa, Pakusari, } \\
\text { Kalisat, } \\
\text { Ledokombo, } \\
\text { Ambulu, Rambipuji } \\
\text { Kencong, } \\
\text { Jenggawah, Gum } \\
\text { mas, Umbulsari, } \\
\text { Tanggul, } \\
\text { Sumberjambe, } \\
\text { Sumbersari, } \\
\text { Sukowono, } \\
\text { Pakusari, Suko } \\
\text { rambi, Jombang, } \\
\text { Balung, }\end{array}$ & $\begin{array}{c}5.569 \\
\text { unit }\end{array}$ & $\begin{array}{l}\text { gula kelapa, } \\
\text { tempe tahu, } \\
\text { kerupuk, tape } \\
\text { singkong, } \\
\text { terasi, batik tulis, } \\
\text { bordir, } \\
\text { konveksi, kapur, } \\
\text { batu merah, } \\
\text { genteng, batu } \\
\text { piring, } \\
\text { anyaman, kayu } \\
\text { aren, } \\
\text { kurungan, mebel } \\
\text { rotan, kere } \\
\text { bambu, } \\
\text { gerabah, } \\
\text { sayangan, } \\
\text { pande besi }\end{array}$ & $\begin{array}{c}\mathrm{Rp} \\
725,625,000\end{array}$ & $\begin{array}{l}\text { di pasarkan ke } \\
\text { pasar lokal }\end{array}$ \\
\hline
\end{tabular}

Sumber: Diolah dari data sekunder, Surabaya, 2009 
Dari uraian di atas maka karakteristik sentra-sentra industri dan daerah pemasaran hasil-hasil industri di selatan dan timur Surabaya dapat dianalisa dan dievaluasi sebagai berikut, bahwa jenis-jenis industri di lokasi penelitian dapat digolongkan minimal menjạdi 7 jenis industri, yaitu aneka kerajinan/anyamam tangan dari bahan bamboo, rotan dan bahan baku lainnya, mebel/ furniture, aneka makanan olahan, perhiasan, hasil tambang, gerabah, dan sulaman.

Secara berturut-turut jumlah unit usaha terbanyak ada di Kabupaten/ Kota Pasuruan, yaitu berjumlah 7.634 unit usaha dengan total investasi sebesar Rp $89,973,670,000$. Kabupaten/Kota Jember berjumlah 5.569 unit usaha dengan total investasi sebesar Rp 725.625.000. Kabupaten/Kota Lumajang berjumlah 2.520 unit usaha dengan total investasi sebesar Rp 2.846.785.000. Kabupaten/Kota Malang 2.326 unit usaha dengan total investasi sebesar Rp 19.907.069.000.. Dan Kabupaten/ Kota Probolinggo berjumlah 1.658 unit usaha dengabn total investasi sebesar Rp 2.991.301.000.

Sementara daerah pemasaran produk-produk hasil industri di lima daerah tersebut lebih dari $50 \%$ dipasarkan dipasaran lokal. Sekitar $30 \%$ dipasarkan di pasaran regional Jawa Timur. Sedangkan sisanya sebesar $20 \%$ dipasarkan di pasaran nasional, yaitu dikirim ke daerahdaerah lain di luar Provinsi Jawa Timur. Khusus untuk hasil industri sulaman Bordir sebanyak $40 \%$ di pasarkan di luar negeri, yaitu ke Eropa, Amerika, dan Timur Tengah.

Untuk pemasaran ke luar daerah, barang atau produk-produk tersebut melewati dua jalur, yaitu jalur darat dan laut. Jalur darat dari sentra-sentra industri lewat Porong di teruskan ke Jawa Tengah dan Jawa Barat lewat jalan darat Pantura. Jalur laut, dari sentra-sentra industri menuju Tanjung Perak lewat Porong diteruskan ke tempat tujuan di luar Provinsi Jawa Timur.

\section{B. Jalur Lintasan dan Jalur Alternatif}

Di wilayah Jawa Timur Profil jalur transportasi angkutan darat dapat dibagi ke dalam 7 wilayah distribusi (lihat Gambar 1). Jalur transportasi ke arah barat, yaitu (1) Surabaya Gresik - Lamongan - Bojonegoro, (2) Surabaya - Gresik - Tuban, (3) Surabaya - Mojokerto - Jombang Nganjuk - Madiun - Ponorogo, ke arah selatan yaitu (4) Surabaya Mojokerto - Kediri - Tulungagung Trenggalek - Ponorogo, (5) ke arah tengah yaitu Surabaya - Malang Lumajang - Jember, ke arah timlur yaitu (6) Surabaya - Pasuruan - Probolinggo - Bampizungi. Ke arah u tara yaitu (7) Surabaya - Madura 


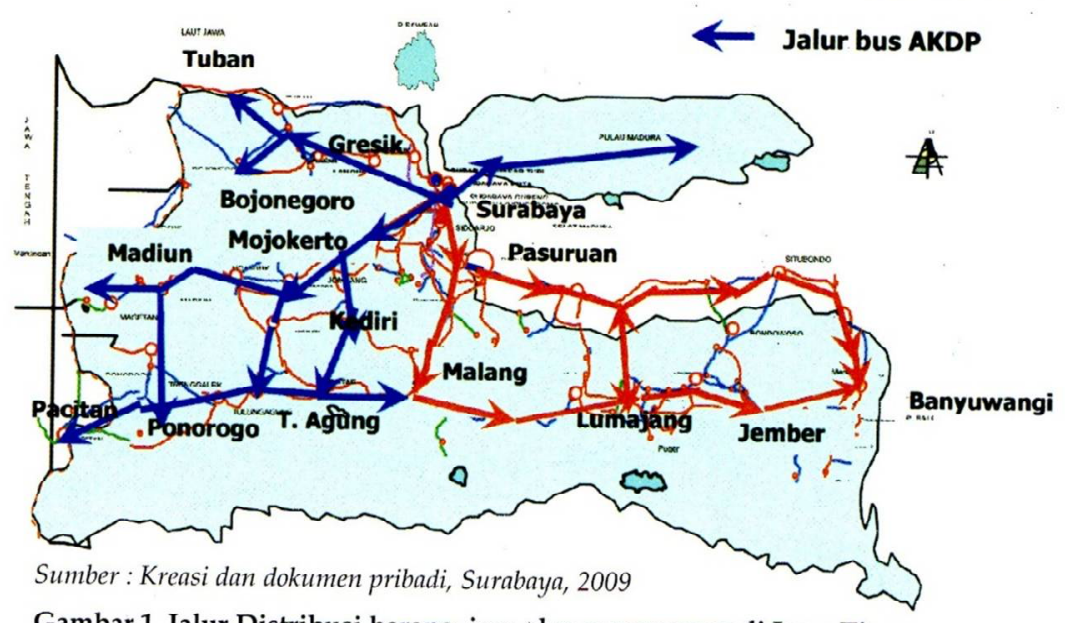

Gambar 1. Jalur Distribusi barang, jasa, dan penumpang di Jawa Timur

Sebelum lumpur Lapindo merusak dan memutuskan jalan Tol Surabaya - Gempol ruas Porong Gempol, semua pergerakan barang dan jasa untuk kepentingan ekspor dan impor dari Surabaya menuju wilayah timur dan selatan Jawa Timur atau sebaliknya semuanya menggunakan dan melewati jalan Tol Surabaya - Gempol ruas Porong Gempol serta jalan arteri Raya Porong, dan sebagian jalan rel Sidoarjo Porong. Begitu juga untuk angkutan penumpang.

Akibat putusnya jalan Tol Surabaya - Gempol ruas Porong Gempol dan tersendatnya jalan raya arteri Porong serta jalan rel pengguna jalan pemerintah mencari jalan alternatif disekitar Sidoarjo dan Mojokerto. Jalan-jalan alternatif tersebut dari arah Surabaya - Malang dan sebaliknya bisa melalui beberapa lintasan, yaitu antara lain, pertama adalah jalan arternatif Surabaya Sepanjang - Krian - Mojosari - Ngoro Industri Persada - Kejapanan -
Gempol - Pandaan - Malang Banyuwangi. Kedua adalah jalan alternatif. Surabaya - Sepanjang Krian - Mojokerto -Mojosari - Ngoro Industri Persada - Kejapanan Gempol - Pandaan - Malang Banyuwangi.

Ketiga adalah jalan alternatif Surabaya - Sidoarjo - Wonoayu Mojosari - Ngoro industri persada Kejapanan - Gempol - Pandaan Malang - Banyuwangi. Keempat adalah lintasan adalah lintasan Surabaya - Sidoarjo - Tanggulangin Tulangan - Mojosari - Ngoro industri persada - Kejapanan - Gempol Pandaan - Malang - Banyuwangi. Kelima adalah lintasan adalah lintasan Surabaya - Sidoarjo - Tanggulangin Tulangan - Mojosari - Ngoro industri persada - Trawas - Prigen - Pandaan Malang - Banyuwangi.

Jalan-jalan alternatif tersebut setiap hari tentunya akan dilintasi oleh kendaraan-kendaraan pribadi, angkutan penumpang umum, maupun angkutan barang dengan kapasitas 
Jurnal Cakrawala Vol.6 No.1 Desember 2011 : 1 - 15

atau tonnase yang sangat berat, yakni di atas 10 ton yang biasanya melewati jalan Tol. Kondisi ini tentunya sangat berbahaya bagi prasarana jalan yang dilalui, karena akan merusak jalanjalan alternatif tersebut. Untuk itu maka peningkatan kapasitas dan kualitas jalan sangat diperlukan dan harus dilaksanakan dengan segera serta dilakukan pengaturan.

Peningkatan kapasitas dan kualitas jalan alternatif tersebut diantaranya adalah perkerasan jalan, pelebaran jalan, pemasangan ramburambu dan marka jalan dan lainlainnya. Serta menerapkan perekayasaan manajemen lalu lintas angkutan jalan. Dengan selektif dan tegas dalam memberikan batas toleransi tonnase. Namun penggunaan dan peningkatan kapasitas dan kualitas jalan alternatif ini haruslah dipergunakan untuk sementara saja. Hal ini dilakukan untuk mencegah kerusakan jalan alternatif lebih lanjut. Selanjutnya untuk jangka menengah dan panjang perlu dibuatkan jalan Tol baru menggantikan jalan Tol lama yang terputus. Merelokasi dan membangun jalan rel baru atau menghidupkan jalan rel yang sudah ada dan tidak terpakai (Priyambodo dan Abdul hamid : 2007).

Atas terputusnya jalan Tol Surabaya - Gempol ruas Porong Gempol dapat dianalisa dan dievaluasi sebagai berikut.

Ruas jalan raya dan jalan rel lintas Surabaya - Malang - Jember (selatan) dan Lintasan Surabaya Pasuruan - Banyuwangi (timur) begitu juga sebaliknya merupakan jalur utama transportasi ekonomi di Jawa Timur. Untuk kepentingan ekspor-impor, maka barang-barang tersebut akan didistribusikan keluar atau masuk Propinsi Jawa Timur melalui pelabuhan Tanjung Perak, Surabaya. Atau pelabuhan-pelabuhan lain di wilayah Propinsi Jawa Timur, yaitu Pelabuhan Tanjungwangi di Banyuwangi, Panarukan, Probolinggo, Situbondo, Bondowoso, dan Pasuruan.

Sementara distribusi barang dan jasa untuk kepentingan ekspor-impor dari sentra-sentra industri dan perdagangan di timur Surabaya serta pergerakan orang sebelum terjadinya tragedi semburan lumpur panas di Porong, Sidoarjo dilayani oleh jalan negara yang membentang di pesisir utara Jawa Timur. Jalur tersebut adalah jalur Banyuwangi - Situbondo Bondowoso-Probolinggo - Pasuruan Sidoarjo (ruas Porong-Gempol) Surabaya. Atau Banyuwangi - Jember - Lumajang - Probolinggo-Pasuruan Sidoarjo (ruas Porong-Gempol) Surabaya.

Sedangkan distribusi barang dan jasa untuk kepentingan ekspor-impor dari sentra-sentra industri dan perdagangan di selatan Surabaya serta pergerakan orang sebelum terjadinya tragedi semburan lumpur panas di Porong Sidoarjo dilayani oleh jalan propinsi yang membentang di wilayah tengah Jawa Timur, yaitu Malang - Sidoarjo (ruas PorongGempol) atau raya arteri Porong Surabaya. Begitu juga sebaliknya.

Selain menggunakan jalan raya, distribusi barang, jasa dan penumpang dari Surabaya ke Malang dan Banyuwangi atau sebaliknya juga bisa menggunakan jalur rel yang melewati Porong, Sidoarjo.

Dari uraian di atas dapat disimpulkan bahwa ruas Porong sangat penting dan vital. Ruas tersebut 
Priyambodo *) Optimalisasi Tingkat Pelayanan .....

merupakan satu-satunya jalur transportasi ekonomi yang dilayani oleh jalan Tol, jalan raya, dan jalan rel yang menghubungkan wilayah Surabaya ke wilayah timur dan selatan. Begitu juga sebaliknya. Sehingga jika ruas Porong ini terputus, baik Tol, jalan raya, maupun jalan rel, maka wilayah selatan dan timur Surabaya untuk keSurabaya dipastikan akan terganggu dan putus sama sekali. Kondisi ini akan menyebabkan pengguna jalan akan menggunakan jalan alternatif (Priyambodo dan Abdul hamid: 2007).

\section{Kondisi Aksesibilitas dan Tingkat Pelayanan Jalan}

\section{Aksesibilitas}

Kondisi koneksitas dan aksesibilitas $\left(\boldsymbol{K}_{i}\right)$ yang dihitung secara kuantitatif dari sisi waktu dan biaya $\left(\boldsymbol{t}_{i d}\right)$ dapat diuraikan sebagai berikut.

Banyaknya zona $(N)$ ada 4 (empat) yaitu lintasan atau aktivitas kegiatan $\left(A_{d}\right)$ di titik Bangil (Sidoarjo - Pasuruan), dititik Pandaan (Sidoarjo Malang), dititik Rejoso (Pasuruan - Probolinggo), dan dititik Singosari (Malang - Gempol). Data-data dimaksud dapat dilihat pada Tabel 2 di bawah ini.

Tabel 2

Aksesibilitas (kuantitatif)

\begin{tabular}{|c|l|c|c|c|c|}
\hline No & \multicolumn{1}{|c|}{ Titik pengamatan } & Tujuan & Jarak/km & Ongkos/Rp & Waktu/jam \\
\hline I & Bangil (Sidoarjo - Pasuruan) & Surabaya & 65,3 & 8333.333 & 2,3 \\
\hline 2 & Pandaan (Sidoarjo - Malang) & Surabaya & 69,3 & 753.333 & 2,1 \\
\hline 3 & Rejoso (Pasuruan - Probolinggo) & Surabaya & 73,4 & 732.5 & 2,8 \\
\hline 4 & Singosar (Malang - Gempol) & Surabaya & 79,3 & 716.667 & 2,3 \\
\hline
\end{tabular}

Sumber: Diolah dari data primer, Surabaya, 2009

Untuk data-data aksesibilitas yang dihitung secara kualitatif berdasarkan persepsi responden (para sopir angkutan barang) yang dihitung dititik Bangil (Sidoarjo - Pasuruan), dititik Pandaan (Sidoarjo - Malang), dititik Rejoso (Pasuruan Probolinggo), dan dititik Singosari (Malang - Gempol) rata-rata bernilai 3,3 dan 3,5. Data-data tersebut dapat dilihat pada Tabel 3 di bawah ini.

Tabel 3

Persepsi Aksesibilitas (kualitatif)

\begin{tabular}{|c|c|c|c|c|c|c|c|}
\hline No & Titik pengamatan & Mudah/1 & Waktu/2 & Biaya/3 & Nyaman/4 & Aman/5 & $\begin{array}{c}\text { Rata- } \\
\text { rata }\end{array}$ \\
\hline 1 & Bangil (Sidoarjo - Pasuruan) & 3,6 & 3,5 & 3,1 & 3,1 & 3,3 & 3,3 \\
\hline 2 & Pandaan (Sidoarjo - Malang) & 3,3 & 3,4 & 3,2 & 3,3 & 3,3 & 3,3 \\
\hline 3 & Rejoso (Pasuruan - Probolinggo) & 3,4 & 3,6 & 3,5 & 3,6 & 3,6 & 3,5 \\
\hline 4 & Singosar (Malang - Gempol) & 3,5 & 3,3 & 3,1 & 3,3 & 3,3 & 3,3 \\
\hline
\end{tabular}

Sumber : Diolah dari data primer; Surabaya, 2009 
Dari uraian di atas koneksitas dan aksesibilitas lintasan dari sentra-sentra industri di wilayah timur dan selatan Surabaya yang menuju Surabaya yang melewati Porong - Gempol ditinjau dari aspek jarak, ongkos, dan waktu tempuh dapat analisa dan dievaluasi sebagai berikut, bahwa rata-rata jarak, ongkos, dan waktu tempuh distribusi barang dari sentra - sentra industri menuju Surabaya yang melewati ruas Porong - Gempol yang dihitung dari titik-titik lokasi di Bangil, Pandaan, Rejoso, dan Singosari rata-rata memerlukan waktu 2,1 - 2,8 jam. Rata-rata ongkos atau biaya perjalanannya per km-nya adalah Rp 9.037,4 sampai Rp 12.761,6. Sementara dalam per jam-nya rata-rata hanya mampu menempuh jarak 26,2 km sampai $34,5 \mathrm{~km}$.
Lebih lanjut berdasarkan persepsi dari pengguna jalan atau para sopir angkutan barang yang melintasi titik-titik yang disurvei ditinjau dari sisi kemudahan, waktu tempuh, biaya, kenyamanan, dan keamanan dapat dianalisa dan dievaluasi sebagai berikut, bahwa di semua titik, yaitu di titik Bangil (Sidoarjo - Pasuruan), titik Pandaan (Sidoarjo - Malang), titik Rejoso (Pasurun - Probolinggo), titik Singosari (Malang - Gempol) rata-rata bernilai 3,3 dan 3,5. Ini artinya aksesibilitas di lintasan tersebut di atas masuk dalam kategori baik, mudah, atau tinggi.

\section{Tingkat Pelayanan Jalan}

Perhitungan volume dan kapasitas serta VCR pada lintasan yang disurvei pada bulan Oktober 2009 dan data VCR pada tahun 2008 dapat dilihat pada Tabel 4 dan 5 di bawah ini.

Tabel 4

\begin{tabular}{|c|l|c|c|c|}
\hline No & \multicolumn{1}{|c|}{ Ruas Jalan } & Kategori & Arti \\
\hline 1 & $\begin{array}{l}\text { Rata-Rata VCR di dacrah Gedangan (arah ke Surabaya) } \\
\text { pada jam-jam sibuk }\end{array}$ & 1.2925 & F & Macet \\
\hline 2 & $\begin{array}{l}\text { Rata-Rata VCR di daerah Gedangan (arah ke Sidoarjo } \\
\text { pada jam-jam sibuk }\end{array}$ & 1.3625 & F & Macet \\
\hline 3 & $\begin{array}{l}\text { Rata-Rata VCR di daerah Porong -Gempol (arah ke } \\
\text { Surabaya) pada jam-jam sibuk }\end{array}$ & 0.7525 & D & Mulai macet \\
\hline 4 & $\begin{array}{l}\text { Rata-Rata VCR di daerah Porong -Gempol ini (arah ke } \\
\text { Malang) pada jam-jam sibuk }\end{array}$ & 0.705 & C & Stabil \\
\hline 5 & $\begin{array}{l}\text { Rata-Rata VCR di daerah Ngoro (arah Mojokerto) pada } \\
\text { jam-jam sibuk }\end{array}$ & 0.1725 & A & Lancar \\
\hline 6 & $\begin{array}{l}\text { Rata-Rata VCR di daerah Bangil (arah Pasuruan) pada } \\
\text { jam-jam sibuk }\end{array}$ & 0.645 & C & Stabil \\
\hline 7 & $\begin{array}{l}\text { Rata-Rata VCR di daerah Bangil (arah Gempol dan } \\
\text { Surabaya) pada jam-jam sibuk }\end{array}$ & 0.745 & C & Stabil \\
\hline 8 & $\begin{array}{l}\text { Rata-Rata VCR di daerah Pandaan -Sukorejo (arah ke } \\
\text { Surabaya) pada jam-jam sibuk }\end{array}$ & 0.63 & C & Stabil \\
\hline 9 & $\begin{array}{l}\text { Rata-Rata VCR di daerah Pandaan -Sukorejo (arah ke } \\
\text { Malang) pada jam-jam sibuk }\end{array}$ & 0.6225 & C & Stabil \\
\hline 10 & $\begin{array}{l}\text { Rata-Rata VCR di daerah Singosari (arah ke Surabaya) } \\
\text { pada jam-jam sibuk }\end{array}$ & 0.7525 & D & Mulai macet \\
\hline
\end{tabular}


Priyambodo *) Optimalisasi Tingkat Pelayanan .....

\begin{tabular}{|c|l|c|c|c|}
\hline 11 & $\begin{array}{l}\text { Rata-Rata VCR di daerah Singosari (arah ke Malang) } \\
\text { pada jam-jam sibuk }\end{array}$ & 0.7625 & D & Mulai macet \\
\hline 12 & $\begin{array}{l}\text { Rata-Rata VCR di daerah Kraksaan (arah ke Paiton) pada } \\
\text { jam-jam sibuk }\end{array}$ & 0.1525 & A & Lancar \\
\hline 13 & $\begin{array}{l}\text { Rata-Rata VCR di daerah Tol Gunungsari (arah masuk } \\
\text { pintu tol) pada jam-jam sibuk }\end{array}$ & 0.1225 & $\mathrm{~A}$ & Lancar \\
\hline 14 & $\begin{array}{l}\text { Rata-Rata VCR di daerah Tol Gunungsari (arah } \\
\text { Gunungsari) pada jam-jam sibuk }\end{array}$ & 0.185 & $\mathrm{~A}$ & Lancar \\
\hline
\end{tabular}

Sumber : Diolah dari data primer, Surabaya 2009

Tabel 5

Rekapitulasi Rata-Rata VCR Tahun 2008

\begin{tabular}{|c|l|c|c|c|}
\hline No & \multicolumn{1}{|c|}{ Ruas Jalan } & $\begin{array}{c}\text { Nilai } \\
\text { VCR }\end{array}$ & $\begin{array}{c}\text { Tingkat } \\
\text { Pelayanan }\end{array}$ & Arti \\
\hline 1 & Porong - Malang & 0,87 & E & Tidak stabil \\
\hline 2 & Porong - Surabaya & 0,79 & D & Mendekati tidak stabil \\
\hline 3 & Bunderan Gempol - Malang & 0,50 & C & Arus stabil \\
\hline 4 & Pasuruan - Probolinggo & 0,68 & C & Arus stabil \\
\hline 5 & Bunderan Gempol - Surabaya & 0,71 & C & Arus stabil \\
\hline 6 & Porong - Pasuruan & 0,49 & C & Arus stabil \\
\hline 7 & Alternatif watukosek & 0,44 & B & Arus stabil \\
\hline 8 & Alternatif kejapanan & 0,41 & B & Arus stabil \\
\hline
\end{tabular}

Sumber: Priyambodo, 2009. Tingkat Pe layanan dan Aksesibilitas Serta Evaluasi Kebijakan Rekonstruksi Jalur Transportasi Pasca Semburan Lumpur Lapindo. Warta Penelitian Perhubungan, Volume 21, Nomor 3, Jakarta.

Dari data-data di atas maka VCR pada titik-titik lintasan tersebut dapat dianalisa dan disevaluasi sebagau berikut, bahwa titik-titik kemacetan di dominasi pada lintasan Gedangan baik dari arah Surabaya maupun arah Sidoarjo, dimana VCR-nya 1,2 dan 1,3 dengan kategori E dan F.

Selanjutnya titik-titik kemacetan diluar ruas tersebut di atas terjadi juga pada titik-titik dilintasan Porong - Gempol arah ke Surabaya dengan VCR 0,75 dengan kategori D. Namun pada tahun 2009 ini VCR di lintasan Porong - Gempol arah Surabaya tersebut jika dibanding dengan tahun 2008 yang lalu mengalami peningkatan pelayanan jalan sekitar $5 \%$ sampai 19,5\%. Yaitu pada tahun 2008 dari Porong Gempol arah ke Malang dari 0,87 menjadi 0,70 pada tahun 2009 . Dan pada tahun yang sama yaitu 2008 dari Porong - Gempol arah ke Surabaya dari 0,79 turun menjadi 0,75 pada tahun 2009 (lihat Tabel 4 dan 5). Penurunan ini disebabkan karena telah berfungsinya jalan-jalan alternatif disekitar Sidoarjo dan Mojokerto.

Sementara titik-titik kemacetan lainnya terjadi juga di titiktitik lintasan Singosari dengan VCR 0,75 dan 0,76 dengan kategori D. Kondisi kemacetan di daerah Singosari ini di perparah dengan tidak adanya jembatan penyeberang-an jalan di lokasi ini. Sehingga menyebabkan banyak orang-orang yang lalu lalang menyeberang jalan di lintasan ini. Sedangkan kondisi stabil dan lancar terjadi di titiktitik Ngoro, Kraksaan, dan Tol 
Jurnal Cakrawala Vol.6 No.1 Desember $2011: 1$ - 15

Gunungsari dengan VCR 0,1 sampai 0,2 dengan kategori $\mathrm{A}$ dan B.

\section{KESIMPULAN}

1. Pemasaran produk-produk industri dari wilayah selatan dan timur Surabaya melewati dua jalur, yaitu jalur darat dan laut. Jalur darat dari sentra-sentra industri lewat Poreng diteruskan ke Jawa Tengah dan Jawa Barat lewat jalan darat Pantura. Jalur laut; dari sentra-sentra industri menuju Pelabuhan Tanjung Perak lewat Porong diteruskan ke tempat tujuan di luar Provinsi Jawa Timur.

2. Titik-titik kemacetan di lintasan Porong dari sentra-sentra industri menuju daerah pemasaran yang melintasi Porong terjadi di lintasan Gedangan baik dari arah Surabaya maupun arah Sidoarjo, dimana VCRnya 1,2 dan 1,3 dengan kategori $F$. Selanjutnya titik-titik kemacetan diluar ruas tersebut di atas terjadi juga pada titik-titik di lintasan Porong - Gempol arah ke Surabaya dengan VCR 0,75 dengan kategori $D$. Namun pada tahun 2009 in VCR Porong - Gempol dibanding dengan tahun 2008 yang lalu merigalami peningkatan pelayanan jalan sekitar $5 \%$ sampai $19,5 \%$. Yaitu pada tahun 2008 dari Porong - Gempol arah ke Malang VCR-nya dari 0,87 menjadi 0,70 pada tahun 2009. Dan pada tahun yang sama yaitu 2008 dari Porong - Gempol arah ke Surabaya VCR-nya dari 0,79 menjadi 0,75 pada tahun 2009 (lihat Tabel 16 dan 17). Peningkatan pelayanan jalan ini disebabkan karena telah berfungsinya jalan-jalan alternatif
disekitarSidoarjo dan Mojokerto.

3. Sementara titik-titik kemacetan lainnya terjadi juga di titik-titik lintasan Singosari dengan VCR 0,75 dan 0,76 dengan kategori $D$. Dimana kondisi ini di perparah dengan tidak adanya jemḅatan penyeberangan jalan, sehingga banyak orang yang lalu lalang menyeberang di lintasan ini yang akhirnya menambah kemacetan di lintasan ini. Sedangkan kondisi stabil dan lancar terjadi di titik-titik Ngoro, Kraksaan, dan Tol Gunungsari dengan VCR 0,1 sampai 0,2 dengan kategori $A$ dan $B$.

4. Aksesibilitas jalan lintas Porong yang dihitung secara kuantitatif (kualitatif yang dikuantitatifkan) di titik-titik Bangil, Pandaan, Rejoso, dan Singosari rata-rata bernilai 3,3 dan 3,5. Ini artinya aksesibilitas jalan di seluruh lintasan tersebut masuk dalam kategori baik, mudah, atau tinggi. Namun jika ditinjau dari aspek jarak, ongkos, dan waktu ratarata distribusi barang dari sentrasentra industri menuju Surabaya yang melewati ruas Porong Gempol rata-rata memerlukan waktu 2,1 - 2, 8 jam. Ongkos atau biaya perjalanannya per km-nya rata-rata $R p$ 9.037,4. sampai $R p$ 12.761,6. dan dalam dalam per jamnya rata-rata bisa menempuh ratarata $26,2 \mathrm{~km}$ sampai $34,5 \mathrm{~km}$.

\section{REKOMENDASI}

Untuk mengoptimalkan tingkat pelayanan jalan lintas Porong, maka kepada Pemerintah Provinsi Jawa Timur direkomendasikan untuk melakukan langkah-langkah sebagai berikut:

Pertama, secara terus menerus 
melakukan perawatan dan pengawasan kondisi jalan alternatif. Serta memperbaiki jalan yang bergelombang dan mema-sang rambu-rambu lalu lintas jalan disepanjang jalan mulai dari Pasuruan, Probolinggo, Situbondo, dan Banyuwangi.

Kedua, membangun jembatan penyeberangan pada titik-titik atau pusat-pusat keramaian yang menyebabkan orang lalu lalang melintasi menyeberang jalan sehingga membahayakan keselamatan dan menimbulkan kema-cetan seperti yang terjadi di daerah Singosari.

Ketiga, meningkatan kualitas dan kapasitas jalan di daerah-daerah karena karakteristik atau kondisi jalan di daerah-daerah yang menuju ke pusatpusat industri masuk dalam kategori jalan kelas III, sementara alat angkut yang masuk ke pusat-pusat industri tersebut, seperti truk-truk kapasitasnya melebihi kelas jalan yang dilaluinya.

Keempat, untuk menguraikan kemacetan pada lintasan-lintasan yang memiliki VCR tinggi terutama di lintasan Gedangan, Porong, Gempol maka pembangunan jalan Tol Baru sebagai pengganti Tol Porong - Gempol yang putus harus segera diselesaikan. Sementara untuk mengurai titik-titik kemacetan di titik-titik atau lintasan lain selain lintasan Gedangan, Porong Gempol perlu dilakukan atau diterapkan traffic management atau pengaturan lalu lintas, misalnya dengan sistem bukatutup.

\section{DAFTAR KEPUSTAKAAN}

Direktorat Jenderal Bina Marga RI, 1997. Manual Kapasitas Jalan Indonesia (MKJI). SWEROAD bekerjasama dengan PT. Bina Karya, Jakarta.
Dinas Perhubungan Propinsi Jawa Timur, 2006. Back Up Sistem Transportasi Mengantisipasi Dampak Lumpur Lapindo, Surabaya.

Dinas Perhubungan Propinsi Jawa Timur, 2006. Dampak Penutupan Lalu Lintas Jalan Raya Porong Terhadap Perekonomian Wilayah Jawa Timur, Surabaya.

Gressando, Julian, 2006. Dasar-Dasar Rekayasa Transportasi Jilid 2Terjemahan. Penerbit Erlangga, Edisi Ketiga, Jakarta.

Morlock, Edward. K, 1995. Pengantar Teknik dan Perencanaan Transportasi. PenerbitErlangga, Jakarta.

Miro, Fidel, 2004. Perencanaan Transportasi Untuk Mahasiswa, Perencana, dan Praktisi. Penerbit PT. ERLANGGA, Jakarta.

Miro, Fidel 2005. Dasar-Dasar Rekayasa Transportasi Jilid 1-Terjemahan. PENERBIT ERLANGGA, Edisi Ketiga, Jakarta.

Nasution, M.N., 2003. Manajemen Transportasi. Penerbit Ghalia Indonesia, Edisi Kedua, Jakarta.

Priyambodo dan Abdul I Iamid, 2007. Kebijakan Publik Rekonstruksi Jalur Transportasi Ekonomi Jawa Timur Pasca Bencana Lumpur Lapindo. Jurnal Manajemen Transportasi, STMT TRISAKTI, Volume VIII, Nomor 03, Jakarta.

Priyambodo, 2009. Tingkat Pelayanan dan Aksesibilitas Serta Evaluasi Kebijakan Rekonstruksi Jalur Transportasi. Pasca Semburan Lumpur Lapindo. Warta Penelitian Perhubungan, Volume 21, Nomor 3, Jakarta.

Tamin, Ofyar Z., 2000. Perencanaan dan Permodelan Transportasi. Penerbit ITB, Edisi ke-2, Bandung. 